\title{
Mangrove Vegetation Mapping Using Sentinel-2A Imagery Based on Google Earth Engine Cloud Computing Platform
}

\section{Luhur Moekti Prayogo}

Marine Science Study Program, Faculty of Fisheries and Marine, Universitas PGRI Ronggolawe, Tuban, Indonesia

\begin{abstract}
A B S T R A C T
Mangroves are trees whose habitat is affected by tides, and their presence has decreased from year to year. Today, mapping technology has undergone many developments, including the availability of images of various resolutions and cloud-based image processing. One of the popular platforms today is the Google Earth Engine. Google Earth Engine is a cloud-based platform that makes it easy to access high-performance computing resources for extensive processing. The advantage of using Google Earth Engine is that users do not have to be IT experts without experts in application development, WEB programming, and HTML. This study aims to conduct a study on mangrove mapping in Gili Genting District with Sentinel-2A imagery using a Google Earth Engine. This location was chosen since there are still many mangroves, especially on the Gili Raja and Gili Genting Islands. From this research, it can be concluded that cloud computing-based Sentinel-2A image processing shows that the vegetation value of NDVI results ranges from 0.923208 to 0.75579 . The classification results show that mangrove forests' overall presence on Gili Genting Island is more expansive than Gili Raja Island with 16.74 ha and 14.75 ha. The use of the Google Earth Engine platform simplifies the analysis process because image processing can be done once with various scripts so that analysis becomes faster.
\end{abstract}

Keywords: Google Earth Engine, Cloud Computing, Mapping, Mangrove, Sumenep

Article History

Received 10 October 21

Received in revised form 1 November 21

Accepted 12 December 21

\section{Introduction}

Mangroves are trees that live in isolated environments and are usually located around the coastline, which is affected by tides (Pemerintah Kabupaten Buleleng, 2019). This tree has many functions in coastal areas, including blocking currents and waves, where various biota live, and absorbing carbon dioxide (CO2) gas. According to Hidayah et al. (2015), mangrove forests, especially in southern Madura, have decreased significantly from year to year. This decrease causes the loss of various functions. It impacts environmental sustainability, such as habitat for several biota and abrasion due to the absence of current and wave barriers (Pemerintah Kabupaten Buleleng, 2019). The importance of mangroves and special monitoring is needed so that their existence can be maintained and optimized to preserve the marine and coastal environment in the future.

Today, technological developments cover various fields. One that is experiencing rapid development in remote sensing technology. Remote Sensing is the science or art for acquiring objects on the earth's surface using instruments and sensors without direct contact with the object being sensed (Lillesand et al., 2004). Objects on the earth's surface can be sensed by remote sensing sensors based on the energy reflection emitted by these objects. According to Danoedoro (2012), remote sensing technology can be divided into two types based on its power source, namely passive and active. Passive remote sensing is a technology that relies on sunlight as a power source and can only make acquisitions during the day. Meanwhile, active remote sensing technology is a technology that has its power source from the sensor or vehicle so that it can make acquisitions during the day and night. The study in this study focuses on passive remote Sensing.

Today, remote sensing technology developments are marked by the presence of various high and medium spatial resolution satellite images. Another thing is evidenced by the availability of a full band with different wavelengths that can be used for monitoring objects on the earth's surface, both visible and invisible. One of the highlights to be studied is the availability of open-source medium resolution satellite imagery for mapping mangrove vegetation such as Sentinel-2A. This image has an advantage over other images because it provides a medium spatial resolution covering Indonesia's entire territory (United States Geological Survey, 2020).

Mangrove mapping currently generally uses remote sensing techniques. Nisaa' (2017) This technique can be relied upon because it produces reasonably good information and requires relatively low costs in a relatively short time compared to terrestrial surveys that are very expensive. In many circumstances, if the research location is steep, steep, and it is not possible to survey directly in the field, remote sensing techniques become a reliable alternative.

Today, along with advances in technology and storage models that no longer use hard drives or memory, a new method of mapping mangrove vegetation has emerged, namely, cloud computing-based remote sensing techniques on the Google Earth Engine. Google Earth Engine is a platform that offers cloud-based environmental data analysis (Gorelick et al., 2017). This platform makes it easy for users because it provides medium resolution image data for various analyzes immediately. Another advantage of the Google Earth Engine is that it provides APIs (Application Programming Interface) that uses JavaScript and Python and can be hosted on Github.

Cloud computing research using the Google Earth Engine is

\footnotetext{
* Corresponding author. Phone : +6285232835685

E-mail address: luhurmoektiprayogo@gmail.com
} 
currently quite rare in Indonesia, both mapping mangrove vegetation or other resources. Research on mangrove mapping using the Google Earth Engine platform outside Indonesia has been carried out by Baloloy et al. (2020) using the Mangrove Vegetation Index (MVI) method on Landsat 8 and Sentinel 2 imagery, values $(r=0.63$ and $0.84, \alpha=0.05)$. Chen et al. (2017) also researched mangrove mapping using the Normalized Difference Vegetation Index (NDVI) method in China using multitemporal Landsat and Sentinel 1A imagery. This research shows that the Google Earth Engine can potentially map mangrove mapping, as evidenced by field ground checks. Then, Mondal et al. (2019) evaluates a combination of several methods of 2 machine learning algorithms, Random Forest (RF), and Classification and Regression Trees (CART) on Sentinel 2 images. From this study, it was found that the combination of methods used was able to produce better accuracy around $90 \%$.

From the explanation above, it is necessary to study mangrove mapping with Sentinel-2A imagery using the Google Earth Engine Cloud Computing Platform in Indonesia. This study aims to see the Platform's effectiveness, mainly if it is applied to the coast. The research location is located in Gili Genting District, Sumenep Regency, Madura. This location was chosen because it has quite many mangrove forests scattered throughout the area, namely the Gili Raja and Gili Genting islands. This study's results can later be used as a basis for research related to mangrove mapping, especially cloud computing-based.

\section{Data and Method}

\subsection{Research Location}

This research was conducted in Gili Genting District, Sumenep Regency, Madura. The location selection was based on the consideration of the presence of mangrove vegetation in the area, especially on Gili Raja Island with a geographical location of $7^{\circ} 13^{\prime} 18.60$ "S, $113^{\circ} 47^{\prime} 46.19^{\prime \prime} \mathrm{E}$ and Gili Genting $7^{\circ} 11^{\prime} 57.52$ "S, $113^{\circ} 54^{\prime} 28.11$ " E. The following are the research locations sourced from base map images (https://earthexplorer.usgs.gov/) in the Gili Genting sub-district, Sumenep Regency, Madura.

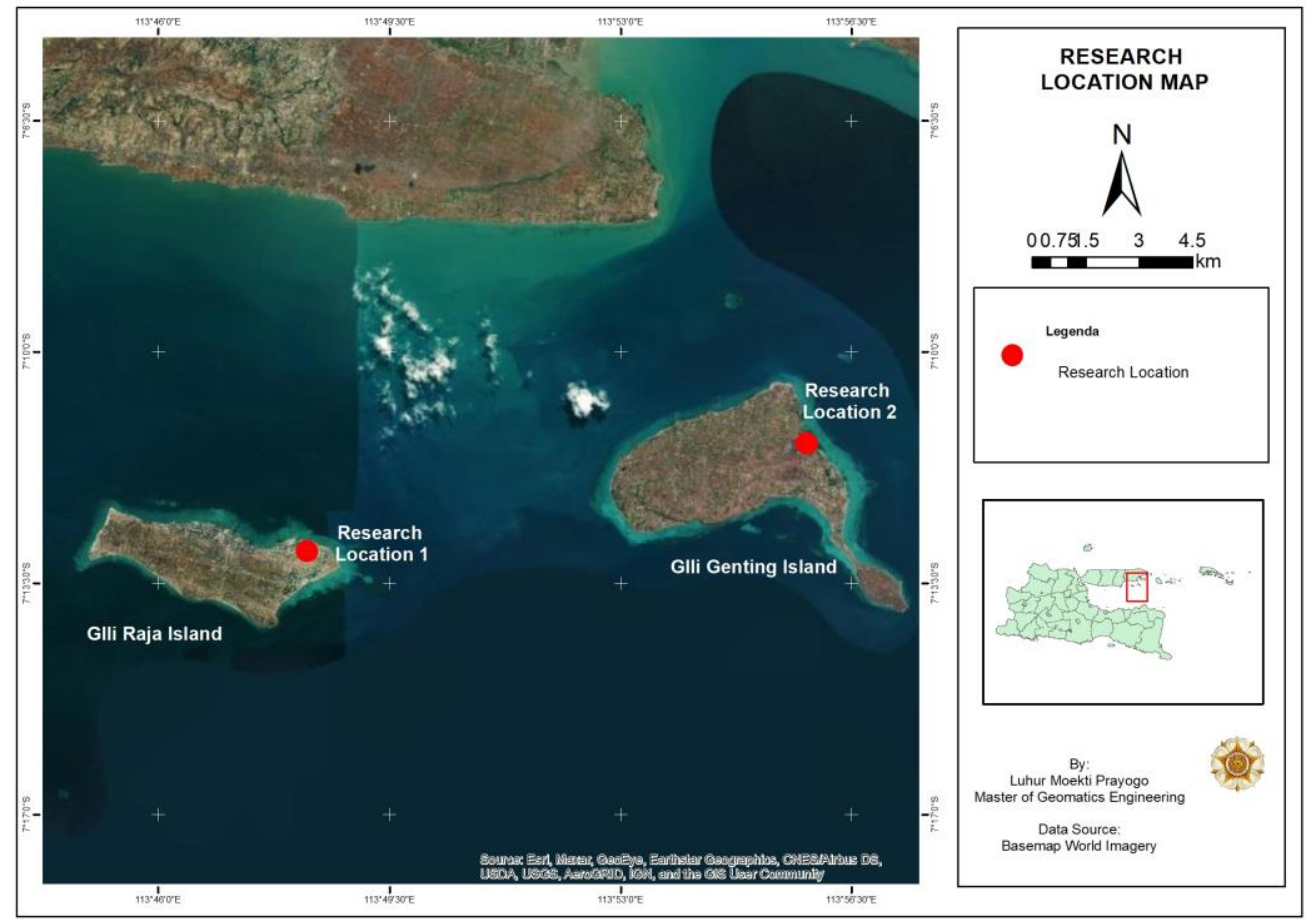

Figure 1. Research locations in the Gili Genting District, Sumenep Regency, Madura

\subsection{Sentinel-2A Imagery}

The image used in this study is a medium resolution image of Sentinel-2A, Gili Genting District, Sumenep Regency, Madura. This image has a temporal resolution of 5 days and a spatial resolution of $10 \mathrm{~m}, 20 \mathrm{~m}$ and $60 \mathrm{~m}$. Sentinel 2 has 13 multispectral channels, including
VNIR and SWIR. This satellite's orbital altitude is $786 \mathrm{~km}$ with an inclination of $98,62^{\circ}$ (Drusch et al., 2012; ESA, 2015). The following is a specification of the Sentinel-2 technique:

Table 1. Technique specifications for Sentinel-2 imagery

\begin{tabular}{cccccc}
\hline Band Number & Wavelength $(\mathbf{n m})$ & Band Width $(\mathbf{n m})$ & Lref $(\mathbf{W m}-\mathbf{2 s r}-\mathbf{1} \boldsymbol{\mu m}-\mathbf{1})$ & SNR @ Lref & Spatial Resolution $(\mathbf{m})$ \\
\hline 1 & 443 & 20 & 129 & 129 & 60 \\
2 & 490 & 65 & 128 & 154 & 10 \\
3 & 560 & 35 & 128 & 168 & 10 \\
4 & 665 & 30 & 108 & 117 & 10 \\
5 & 705 & 15 & 74.5 & 89 & 20 \\
6 & 740 & 15 & 68 & 105 & 20 \\
7 & 783 & 20 & 67 & & 20
\end{tabular}




\begin{tabular}{|c|c|c|c|c|c|}
\hline 8 & 842 & 115 & 103 & 174 & 10 \\
\hline $8 b$ & 865 & 20 & 52.5 & 72 & 20 \\
\hline 9 & 945 & 20 & 9 & 114 & 60 \\
\hline 10 & 1380 & 30 & 6 & 50 & 60 \\
\hline 11 & 1610 & 90 & 4 & 100 & 20 \\
\hline 12 & 2190 & 180 & 1.5 & 100 & 20 \\
\hline
\end{tabular}

Source: (Drusch et al., 2012; Van der Meer et al., 2014; Oktaviani \& Kusuma, 2017)

Sentinel-2 imagery has the same local time as Landsat and SPOT images so that for multitemporal analysis it can combine the two images into Sentinel-2 images (Drusch et al., 2012; ESA, 2015). The preprocessing stage includes radiometric correction, which is used to correct the image's spectral value (Danoedoro, 2012).This correction uses the equation $\mathrm{L} \lambda=$ MLQcal $+\mathrm{AL}$ by using the minimum and maximum reflectance values. The atmospheric effect in the image causes the sensor reflection value to not reflect the object in the field due to the scattering and absorption factors (Danoedoro, 2012).

\subsection{Normalized Difference Vegetation Index (NDVI)}

This study uses the Normalized Difference Vegetation Index (NDVI) method. This method uses Red and Near-Infrared bands in Sentinel-2A imagery. All vegetation in the image will be detected easily using this method. To distinguish between mangrove and nonmangrove vegetation, will be check was carried out on Google Earth imagery. The similarities of the NDVI method are as follows (Sobrino et al., 2008):

$$
N D V I=\frac{(\text { Near } \text { Infrared }- \text { Red })}{(\text { Near Infrared }+ \text { Red })} \ldots \ldots \ldots
$$

Where;

NDVI

Near Infrared

: Normalized Difference Vegetation Index

Red

: Near Infrared Band from Sentinel-2A imagery

: Red Band from Sentinel-2A imagery

\subsection{Google Earth Engine Platform}

Technological developments are marked by supercomputers' availability with high capabilities in cloud-based processing (Cossu et al., 2010; Nemani et al., 2011; Gorelick et al., 2017). Simultaneously, the availability of petabyte-scale remote sensing data has been made freely available from various US Geological Survey and NOAA (Gorelick et al., 2017). However, to access big data sizes above requires very high costs starting from a strong network, large storage, computer capabilities with high specifications and reduced file format (Gorelick et al., 2017). Google Earth Engine is a cloud-based platform that makes it easy to access high-performance computing resources for extensive processing (Gorelick et al., 2017). The advantage of using Google Earth Engine is that users do not have to be IT experts without experts in application development, WEB programming and HTML. The following is the design architecture of the Google Earth Engine (Gorelick et al., 2017):

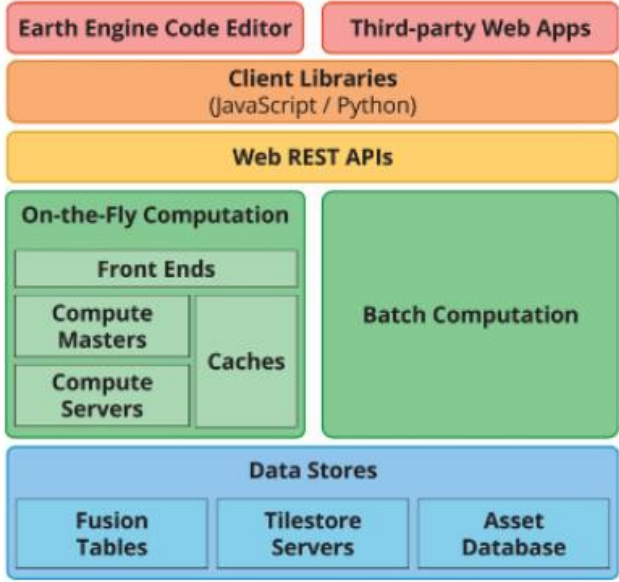

Figure 2. Google Earth Engine design architecture (Gorelick et al., 2017)

The image above is a simplified Google Earth Engine architecture (Gorelick et al., 2017). The queries on the platform are based on a functional evaluation composition that incorporates operations on the database. More than 800 functions consist of mathematical, geostatistical, algebraic functions, application of arbitrator functions to the database and statistical calculation functions on images. Google Earth Engine is also equipped with bit manipulation, edge detection, convolution matrices, and image operations for both bands and pixels (Gorelick et al., 2017).

\section{Results and Discussion}

\subsection{Research Location}

This research was conducted in Gili Genting district, Sumenep Regency, Madura. The research location is limited to two islands in the district, namely Gili Raja and Gili Genting Island. The location was chosen because it still has a lot of mangrove vegetation. Gili Raja Island has quite a lot of mangrove vegetation in the north and east. While on Gili Genting Island, mangrove locations are scattered in almost all parts of the coast. The beaches on the two islands have sandy and rocky morphology. The following is the distribution of mangroves in the two regions using Google Earth imagery in 2019: 


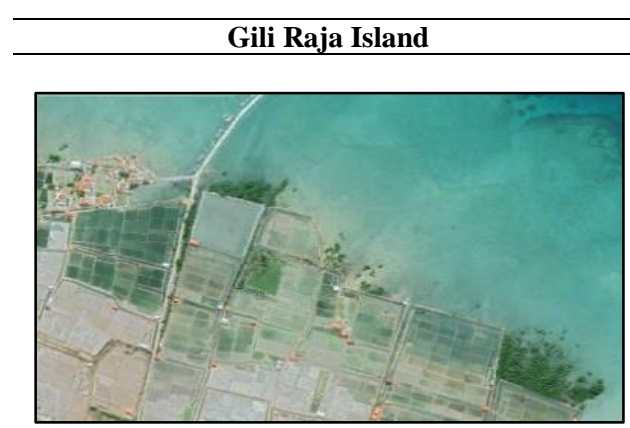

North

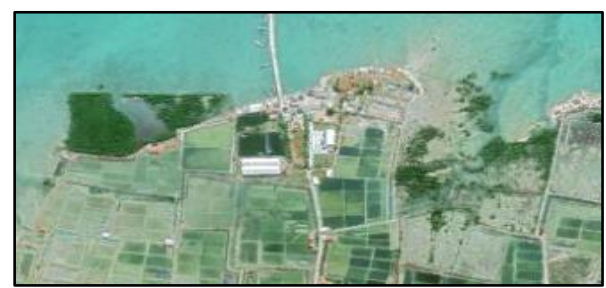

North

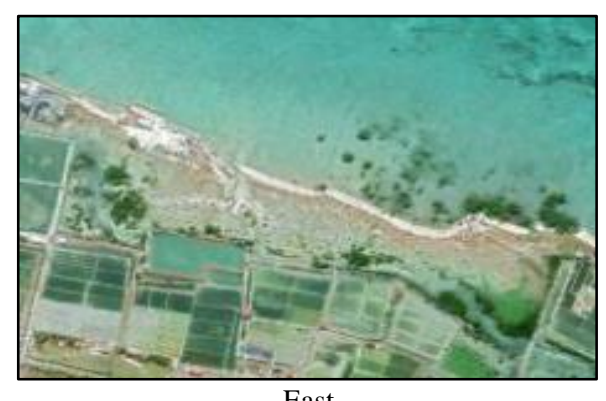

East

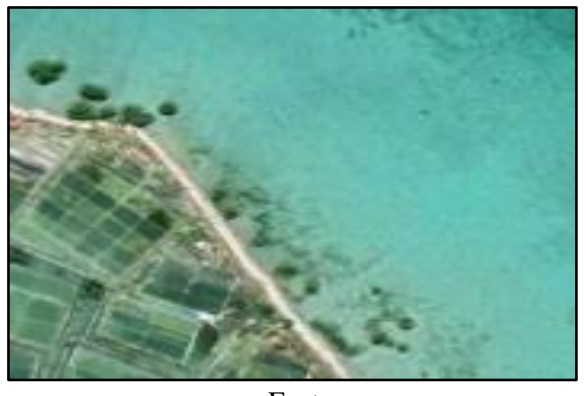

East

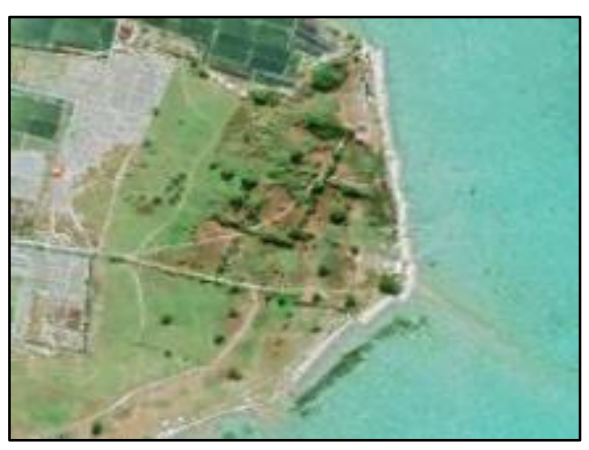

Gili Genting Island

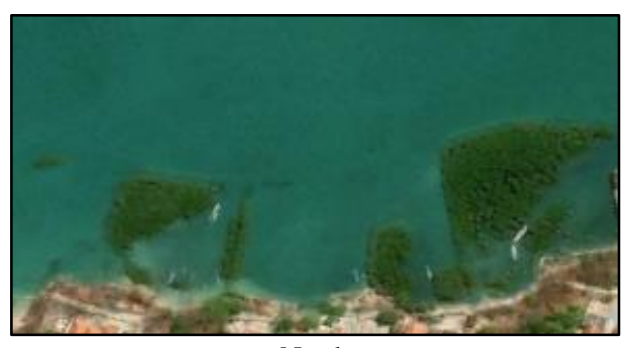

North

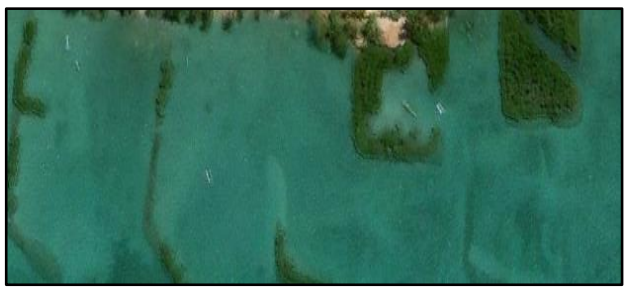

South

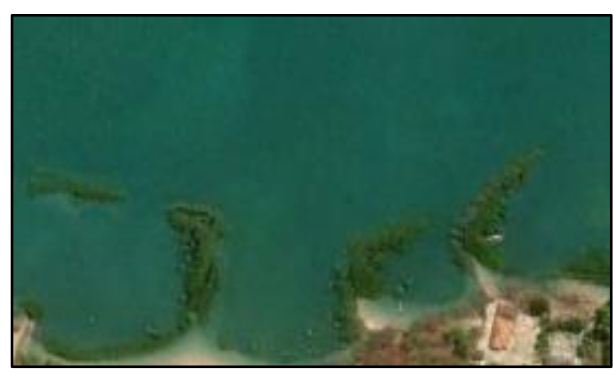

North

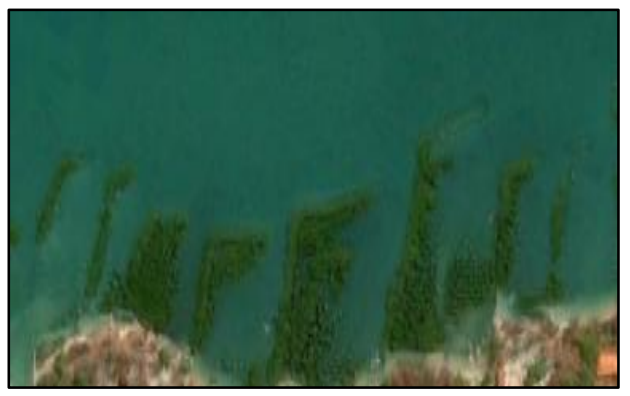

North

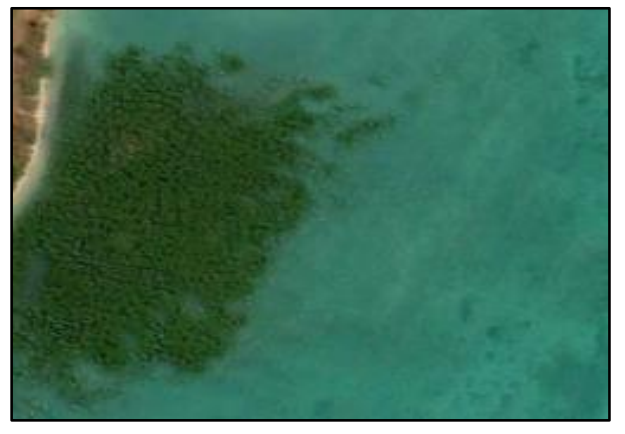

East 


\section{East}

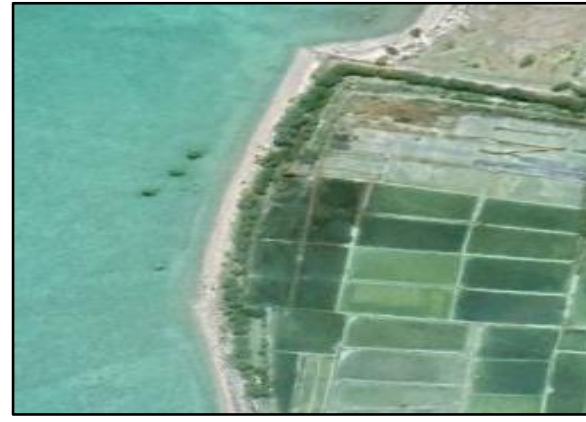

West

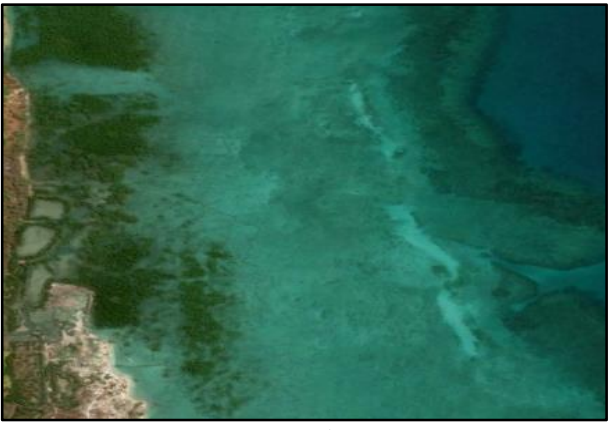

North

Figure 3. Distribution of mangrove vegetation on the islands of Gili Raja and Gili Genting, Madura

Mapping mangrove vegetation using Google Earth Engine begins with selecting the image used. This research uses Sentinel $2 \mathrm{~A}$ imagery with 2019 recording with minimum cloud cover. The location selection is made by clip (boundary); which can be done when writing the script. Clip boundary covers the area of two islands in Gili Genting District which are in Polygon. The following are the results of the import boundary used in this study:

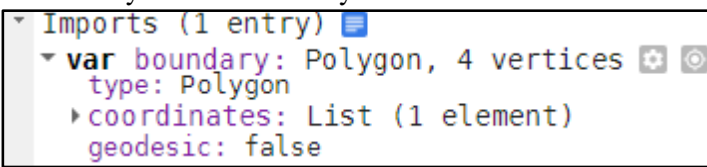

\subsection{Image Processing}

Figure 4. Import Boundary

Then enter the bands in the processing, namely Band 4, Band 3 and Band 2. This step is done to obtain an image display that makes it easier to identify vegetation. Whereas in NDVI processing, the entered bands are Band 8 (Near-Infrared) and Band 3 (Red). The NDVI calculation is a division of Near Infrared-Red / Near-Infrared + Red. So that writing the script can be done as follows:

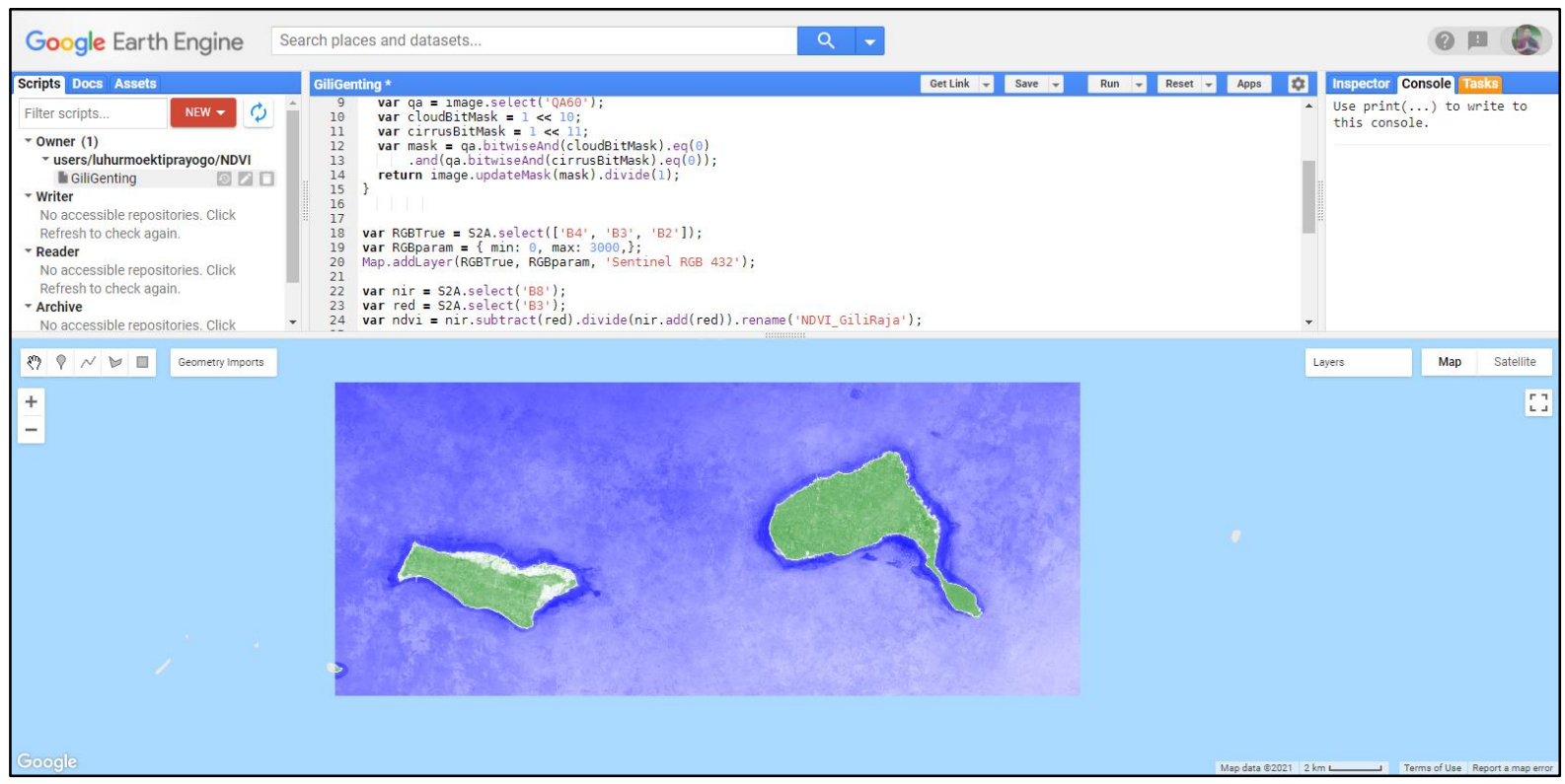

Figure 5. Sample of NDVI analysis script using Google Earth Engine

NDVI transformation is only carried out on mangrove vegetation objects. The results of the NDVI transformation have values ranging from -1 to 1 . This study produces pixel values ranging from 0.923208 to 0.75579 . Based on the pixel value, the classification is divided into three categories, namely high, medium and low. The NDVI analysis found that the most mangrove distribution of Gili Raja Island was in the northern part. From the classification that has been carried out, it shows that mangrove with dense (high) cover has an area 
of 7.39 ha, the medium cover is 5.83 ha and the sparse (low) cover is 1.53 ha. so that the total area of mangrove vegetation on the island of Gili Raja is 14.75 ha. Then, the mangrove vegetation of Gili Genting's island is wider than the island of Gili Raja. This island has dense (high) mangrove vegetation covering an area of 13.36 ha. However, with a moderate density level, the mangroves of Gili Genting Island only have $1.5 \mathrm{ha}$ and a rare (low) density of $1.88 \mathrm{ha}$. Therefore, the mangroves on Gili Genting Island are more expansive than those on Gili Raja Island. The following is a table of the area of mangrove vegetation for each region and several mangrove locations on the Gili Raja island (Table
2).

Table 2. Extent of mangrove vegetation

\begin{tabular}{ccc}
\hline Category & Gili Raja (ha) & Gili Genting (ha) \\
\hline High & 7.39 & 13.36 \\
Medium & 5.83 & 1.5 \\
Low & 1.53 & 1.88 \\
Total & $\mathbf{1 4 . 7 5}$ & $\mathbf{1 6 . 7 4}$ \\
\hline
\end{tabular}

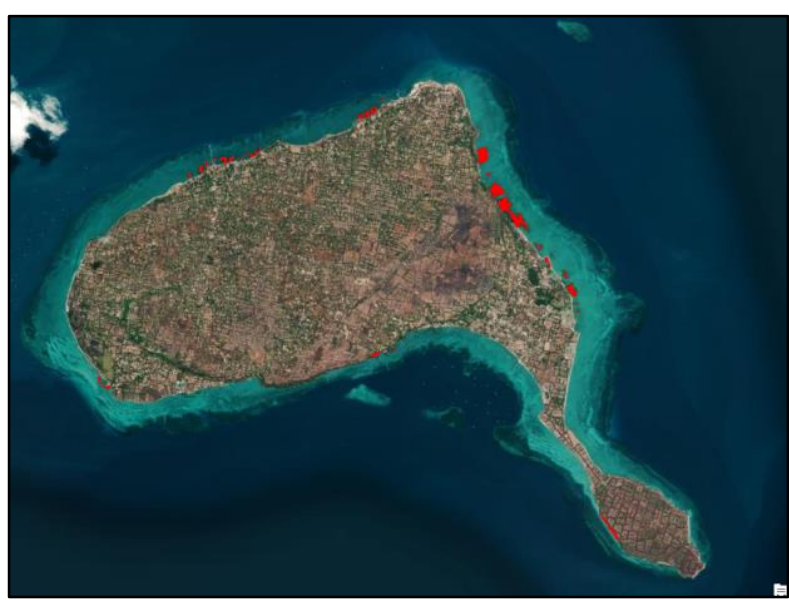

Gili Genting Island

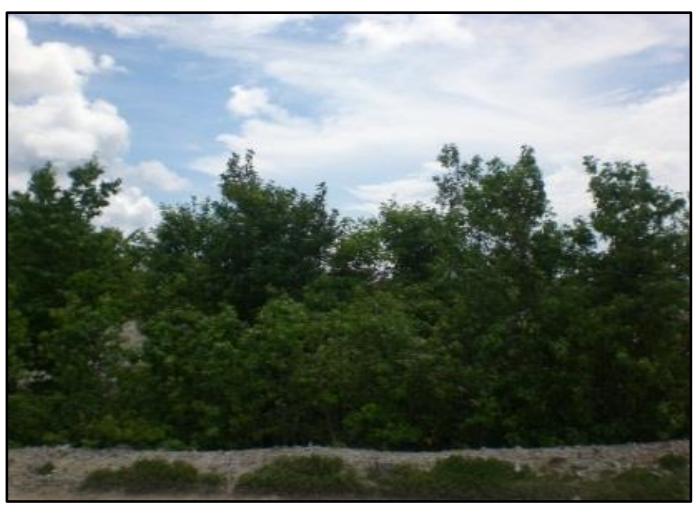

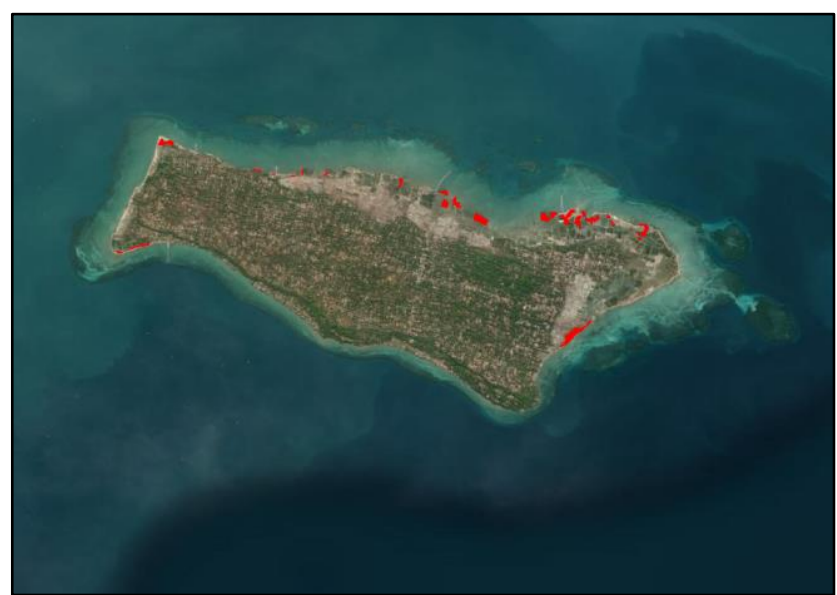

Gili Raja Island

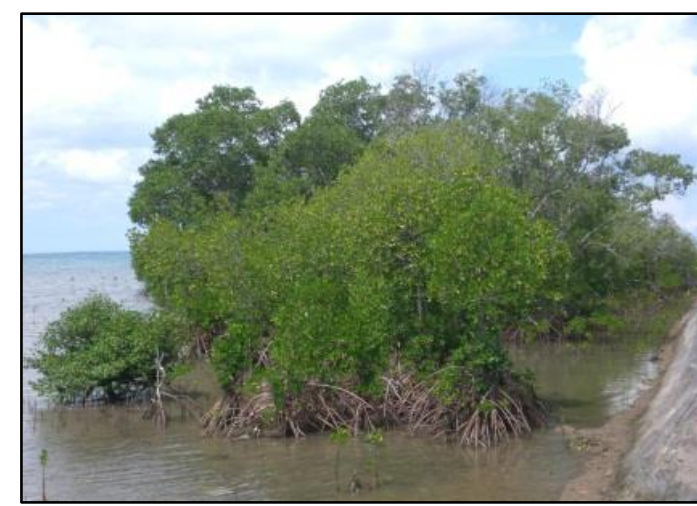

Figure 6. Mangrove condition in Gili Genting District, Sumenep Regency - Madura. The red color on the map is the classified mangrove vegetation

\section{Conclusions}

From this research, it can be concluded that from cloud computing-based Sentinel-2A image processing shows that the vegetation value of NDVI results ranges from -0.923208 to 0.75579 . Gili Raja Island has a total area of mangrove vegetation of 14.75 ha with dense vegetation high $=7.39$ ha, medium $=5.83$ ha and Low $=1.53$ ha. The vegetation cover on Gili Genting Island is more expansive than the Gili Raja Island with a total of 16.74 ha. The details of this amount include dense vegetation high $=13.36$ ha, medium $=1.5$ ha and low $=$ 1.88 ha. The use of the Google Earth Engine platform simplifies the analysis process because image processing can be done once with various scripts so that analysis becomes faster.

\section{Acknowledgment}

The author would like to thank Labsig Inderaja for providing knowledge for the use of the Google Earth Engine platform. 


\section{References}

ESA, E. S. A. (2015). Sentinel-2 User Handbook. In Sentinel-2 User Handbook (p. 64).

Baloloy, A. B., Blanco, A. C., Raymund Rhommel, R. R. C., \& Nadaoka, K. (2020). Development and application of a new mangrove vegetation index (MVI) for rapid and accurate mangrove mapping. ISPRS Journal of Photogrammetry and Remote Sensing, 166, 95-117. https://doi.org/10.1016/j.isprsjprs.2020.06.001.

Bangqian Chen, Xiangming Xiao, Xiangping Li , Lianghao Pan, Russell Doughty, J. M., Jinwei Dong, Yuanwei Qin, Bin Zhao, Zhixiang Wua, Rui Sun, Guoyu Lan, G. X. a, \& Nicholas Clinton, C. G. (2017). A mangrove forest map of China in 2015: Analysis of time series Landsat 7/8 and Sentinel-1A imagery in Google Earth Engine cloud computing platform. ISPRS Journal of Photogrammetry and Remote Sensing, 131, 104-120. https://doi.org/http://dx.doi.org/10.1016/j.isprsjprs.2017.07.01 1.

Cossu, R., Petitdidier, M., Linford, J., Badoux, V., Fusco, L., Gotab, B., Hluchy, L., Lecca, G., Murgia, F., Plevier, C., Renard, P., Schwichtenberg, H., de Cerff, W. S., Tran, V., \& Vetois, G. (2010). A roadmap for a dedicated Earth Science Grid platform. Earth Science Informatics, 3, 135-148. https://doi.org/10.1007/s12145-010-0045-4.

Danoedoro, P. (2012). Pengantar Pengindraan Jauh Digital. In Benedicta Rini W (Ed.), Penerbit ANDI (1st ed.). Penerbit ANDI. ISBN: 9789792931129, 1-397 pp.

Drusch, M., Del Bello, U., Carlier, S., Colin, O., Fernandez, V., Gascon, F., Hoersch, B., Isola, C., Laberinti, P., Martimort, P., Meygret, A., Spoto, F., Sy, O., Marchese, F., \& Bargellini, P. (2012). Sentinel-2: ESA's Optical High-Resolution Mission for GMES Operational Services. Remote Sensing of Environment, 120, 25-36. https://doi.org/10.1016/j.rse.2011.11.026.

Gorelick, N., Hancher, M., Dixon, M., Ilyushchenko, S., Thau, D., \& Moore, R. (2017). Google Earth Engine: Planetary-scale geospatial analysis for everyone. Remote Sensing of Environment, 202, 18-27. https://doi.org/10.1016/j.rse.2017.06.031.

Hidayah, Z., Rosyid, D. M., \& Armono, H. D. (2015). GIS application in monitoring distribution of mangrove ecosystem of Southern Madura. Ecology, Environment and Conservation, 1-14.

Lillesand, T. M., Kiefer, R. W., \& Chipman, J. W. (2004). Remote sensing and image interpretation. In Nev York Chichester Brisbane Toronto 6IS s.

Mondal, P., Liu, X., Fatoyinbo, T. E., \& Lagomasino, D. (2019). Evaluating combinations of sentinel-2 data and machinelearning algorithms for mangrove mapping in West Africa. Remote Sensing, 11(2928), 1-16. https://doi.org/10.3390/rs11242928.

Nemani, R., Votava, P., Michaelis, A., Melton, F., \& Milesi, C. (2011). Collaborative supercomputing for global change science. Eos, 92(13), 109-110. https://doi.org/10.1029/2011EO130001.
Oktaviani, N., \& Kusuma, H. A. (2017). Pengenalan Citra Satelit Sentinel-2 Untuk Pemetaan Kelautan. OSEANA, XLII(3), 4055. https://doi.org/10.14203/oseana.2017.vol.42no.3.84.

Pemerintah Kabupaten Buleleng. (2019). Pentingnya hutan mangrove bagi lingkungan hidup. https://www.bulelengkab.go.id/detail/artikel/pentingnya-hutanmangrove-bagi-lingkungan-hidup-88 (Accessed January 18, 2021).

Ratri Ma'rifatun Nisaa', N. K. (2017). Pemetaan Kerusakan Mangrove Menggunakan Citra Landsat Oli Di Delta Mahakam, Kalimatan Timur. Prosiding Seminar Nasional Geografi UMS, 67-77. https://doi.org/978-602-361-072-3.

Sobrino, J. A., Jiménez-Muñoz, J. C., Sòria, G., Romaguera, M., Guanter, L., Moreno, J., Plaza, A., \& Martínez, P. (2008). Land surface emissivity retrieval from different VNIR and TIR sensors. IEEE Transactions on Geoscience and Remote Sensing, 316-327. https://doi.org/10.1109/TGRS.2007.904834.

United States Geological Survey. (2020). USGS EROS Archive Sentinel-2. https://doi.org/Sentinel-2 Digital Object Identifier (DOI) number: /10.5066/F76W992G (Accessed January 17, 2021).

Van der Meer, F. D., van der Werff, H. M. A., \& van Ruitenbeek, F. J. A. (2014). Potential of ESA's Sentinel-2 for geological applications. Remote Sensing of Environment, 128, 124-133. https://doi.org/10.1016/j.rse.2014.03.022. 